\title{
Metabolic Syndrome Increases the Risk of Ischemic Stroke in Women
}

\author{
Kazuo Takahashi ${ }^{1}$, Hirokazu Bokura ${ }^{1}$, Shotai Kobayashi ${ }^{2}$, Kenichi Iijima ${ }^{1}$, \\ Atsushi Nagai ${ }^{3}$ and Shuhei Yamaguchi ${ }^{1}$
}

\begin{abstract}
Background Metabolic syndrome is a characterized by a cluster of cardiovascular risk factors, including visceral obesity, insulin resistance, dyslipidemia, and hypertension. The criteria for diagnosing metabolic syndrome differ among ethnic groups, due in part to differences in eating habits and body build. Little is known about the relationship between metabolic syndrome and ischemic stroke in Asian countries. The aim of this study was to investigate the relationship between metabolic syndrome and first-time ischemic strokes.

Subjects \& Methods Study subjects were 1,493 Japanese adults aged 55 years-old or older with no diabetes mellitus, no history of stroke and no neurological abnormalities, who participated in a voluntary neurological health screening at the Institute of Shimane Health Science, Japan (767 men, $62.0 \pm 5.9$ years old at entry and 726 women, $61.8 \pm 5.1$ years old at entry). All subjects were given an annual clinical stroke questionnaire. Clinical details of patients who reported strokes were confirmed with the attending physicians. Each subject was evaluated for an average of $6.4 \pm 3.8$ years. Metabolic syndrome was defined using the modified criteria for Japanese population published in April 2005.

Results Metabolic syndrome was diagnosed in $11.0 \%$ of men and $1.1 \%$ of women. Adjusting for age and smoking, female subjects with metabolic syndrome had a 23.1-fold increased risk of suffering ischemic strokes [95\% confidence interval (CI), 2.7-196], whereas metabolic syndrome did not increase the risk of ischemic stroke in men.

Conclusions Metabolic syndrome is more likely to influence a risk for ischemic stroke in women than in men.
\end{abstract}

Key words: metabolic syndrome, ischemic stroke, risk factors, women

(DOI: 10.2169/internalmedicine.46.6094)

\section{Introduction}

Metabolic syndrome is defined as a cluster of risk factors for vascular disease (1). A report by the National Cholesterol Education Program Adult Treatment Panel III (NCEP/ ATP III) outlines the definition of metabolic syndrome for clinical use in Western countries (2). Based on this definition, metabolic syndrome is diagnosed if the patient has three or more of the following risk factors: high fasting glucose levels, high blood pressure, low high-density lipoprotein levels, high triglycerides, and abdominal obesity. Prospective cohort studies have shown that metabolic syndrome is associated with increased morbidity or mortality not only from cardiovascular disease (3-9) but also from ischemic stroke (10-13). However, limited information is available regarding the relationship between metabolic syndrome and ischemic stroke in Asian countries. In assessing this relationship in the Japanese population, there are two notable differences between Japanese and Western populations. First, because Asians tend to have smaller body builds and a lower percentage of body fat, the defined cut-off value for the waist circumference is inappropriate. Indeed, this discrepancy has been pointed out in other reports $(14,15)$. Secondly, based on the Hisayama study in Japan (16) and the Framingham study in United States of America $(17,18)$, the

${ }^{1}$ Department of Neurology, Shimane University School of Medicine, Izumo, ${ }^{2}$ Director, Shimane University Hospital, Izumo and ${ }^{3}$ Department of Laboratory Medicine, Shimane University School of Medicine, Izumo

Received for publication June 29, 2006; Accepted for publication November 1, 2006

Correspondence to Dr. Kazuo Takahashi, kazuo-ta@med.shimane-u.ac.jp 
incidence of cerebral infarction in Japanese populations is three to four times higher than in Caucasian populations. In contrast, the incidence of myocardial infarction is five to six times higher in the Caucasian population than in the Japanese population.

In April 2005, the national Metabolic Syndrome Criteria Study Group published criteria for diagnosing metabolic syndrome in the Japanese population (19). Because there are major differences between populations, the relationship between metabolic syndrome and ischemic stroke incidence in Asian populations merits reevaluation. Here, we examined the incidence of ischemic stroke in Japanese subjects with and without metabolic syndrome.

\section{Subjects and Methods}

\section{Subjects}

Study subjects were 1,563 Japanese adults aged 55 yearsold or older with no diabetes mellitus, no history of stroke and no neurological abnormalities, who participated in a voluntary health screening of brain between 1988 and 2002. The subjects wished to receive the health screening of brain at their own expense. Therefore, this was not a populationbased study. Information about medical events occuring during the study period was acquired by questionnaire. At the end of 2004, we had obtained regular medical information from 767 men (age range: 55-91 years, mean age: $62.0 \pm$ 5.9 years old at entry) and 726 women (age range: 55-80 years, mean age: $61.8 \pm 5.1$ years old at entry). The subjects were followed for an average of $6.4 \pm 3.8$ years $(55-5,549$ days), with 850 subjects being followed for more than 5 years. The study was approved by the local Ethics Committee of our university hospital and informed consent for this study was obtained from all subjects according to institutional guidelines.

\section{Assessment of ischemic stroke}

For subjects who reported having strokes, we confirmed the details of the illness in a telephone interview, and followed up with the attending physician to differentiate between ischemic and hemorrhagic stroke. We also confirmed details of the stroke by direct medical examination and MRI when possible.

\section{Cerebrovascular risk factors}

Cerebrovascular risk factors were assessed by interviewing the subjects, and by conducting physical examinations and blood tests. Blood pressure was measured using a sphygmomanometer after $15 \mathrm{~min}$ of rest. Complete blood counts, serum lipids [total cholesterol (T-cho), triglycerides (TG), and HDL cholesterol (HDL-C)], fasting blood glucose, electrocardiogram, and body mass index (BMI) were determined on the first day of the study. Hypertension was defined as a systolic blood pressure of $140 \mathrm{mmHg}$ or higher, a diastolic blood pressure of $90 \mathrm{~mm} \mathrm{Hg}$ or higher, or a his- tory of hypertension as reported by the subject. Diabetes mellitus was defined as a fasting blood glucose level $\geq 126$ $\mathrm{mg} / \mathrm{dl}(7.0 \mathrm{mmol} / \mathrm{L})$ or diagnosed disease as reported by the subject. Hypercholesterolemia was defined as T-cho $\geq 240$ $\mathrm{mg} / \mathrm{dl}$. The BMI was defined as baseline weight (kilograms) divided by the square of height (meters). Smokers were defined as any subject whose smoking index (number of cigarettes/day xnumber of years) exceeded 200. Regular alcohol consumption was defined as $58 \mathrm{~g}$ or more of alcohol per day.

\section{Definition of metabolic syndrome}

According to the metabolic syndrome criteria for Japanese subjects, waist circumference is an essential causative component of the metabolic disorder. According to these criteria, metabolic syndrome was diagnosed if the subject had central obesity and two or more of the following components: elevated blood pressure, dyslipidemia, and fasting hyperglycemia. Central obesity was defined as a waist circumference of $\geq 85 \mathrm{~cm}$ in men and $\geq 90 \mathrm{~cm}$ in women. This cutoff value for central obesity corresponds to $\geq 100 \mathrm{~cm}^{2}$ of visceral fat as estimated by abdominal CT scan for the average Japanese person (19). Elevated blood pressure was defined as a systolic blood pressure of $\geq 130 \mathrm{~mm} \mathrm{Hg}$ and/or a diastolic blood pressure of $\geq 85 \mathrm{~mm} \mathrm{Hg}$. Elevated fasting glucose was defined as a fasting glucose level $\geq 110 \mathrm{mg} / \mathrm{dl}(6.1$ $\mathrm{mmol} / \mathrm{L}$ ). Dyslipidemia was defined as a plasma TG level of $\geq 150 \mathrm{mg} / \mathrm{dl}$ and/or HDL-C level of $<40 \mathrm{mg} / \mathrm{dl}$. As waist circumference was not measured as a part of our health screening until March 2005, we used BMI for the definition of central obesity. The correlation between waist circumference and BMI was used to determine the appropriate cutoff value for BMI. This correlation was based on data gathered between March 2005 and October 2005. As a waist circumference of $\geq 85 \mathrm{~cm}$ in men and $\geq 90 \mathrm{~cm}$ in women corresponded to BMIs of $\geq 25$ (Fig. 1) and $\geq 29$ (Fig. 2), respectively, we used these numbers as cut-off values for central obesity throughout the study.

\section{Statistical analysis}

We used Student's t-test for group comparisons of parametric variables. The Fisher exact test or chi-square test was used for nonparametric statistics. The Cox proportional hazards regression model was used to obtain the adjusted relative risks (RRs) and 95\% confidence intervals (CIs) in reference to metabolic syndrome. The outcome variable was incidence of ischemic stroke. The data were adjusted for age and smoking. All statistical analyses were performed using SPSS 14.0 statistical package (SPSS Inc). Differences with $\mathrm{P}<.05$ were considered significant.

\section{Results}

Metabolic syndrome was present in 84 of 767 men $(11.0 \%)$ and 8 of 726 women $(1.1 \%)$. Ischemic stroke occurred in 35 of 767 men $(4.6 \%)$ and in 15 of 726 women 


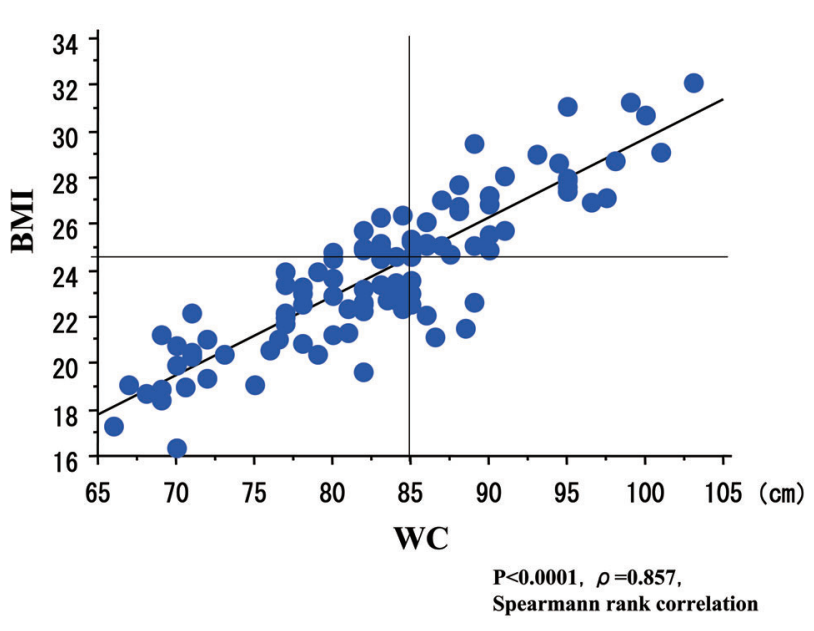

Figure 1. Correlation of body mass index (BMI) and waist circumference (WC) in men ( $\mathrm{n}=104)$. A WC of $\geq 85 \mathrm{~cm}$ in men corresponded to BMIs of $\geq 25$. This data was collected from consecutive participants in our health screening of brain between March 2005 and October 2005.

(2.1\%). Table 1 lists the clinical and biochemical characteristics of the participants. Significant differences between the participants with and without metabolic syndrome were found for all of the components of metabolic syndrome, with the exception of the HDL level among women. There were no significant differences based on age, smoking, atrial fibrillation, T-cho $\geq 240 \mathrm{mg} / \mathrm{dl}$, or follow-up period in both sexes.

Figure 3 shows the cumulative risks for ischemic stroke in men (A) and women (B). The age- and smoking-adjusted RRs for ischemic stroke in women with metabolic syndrome was 23.1 (95\% CI: 2.7-196), whereas there was no significant difference between men with and without metabolic syndrome.

We also used Fisher's exact test to compare the incidence of ischemic stroke in subjects with metabolic syndrome to that in women without metabolic syndrome, because the number of women with metabolic syndrome was unexpectedly small $(n=8)$. However Fisher's exact test did not show that metabolic syndrome increases the risk of ischemic stroke significantly even in women $(\mathrm{p}=0.16)$, when the subset of women subjects followed for 3 to 6 years was analyzed, the difference between the two groups was significant $(\mathrm{p}=0.04$, Table 2).

\section{Discussion}

This study showed that metabolic syndrome increases the risk of ischemic stroke in women but not in men. To our knowledge, there are currently four published cohort studies that examined the association between metabolic syndrome and stroke. The Northern Manhattan study (10), which included Hispanic, African-American, and Caucasian subjects, reported an increased risk of stroke among women with metabolic syndrome [Hazard ratio $(\mathrm{HR}=2.1)$ ] compared to men $(\mathrm{HR}=0.9)$. Koren-Morag et al similarly reported that

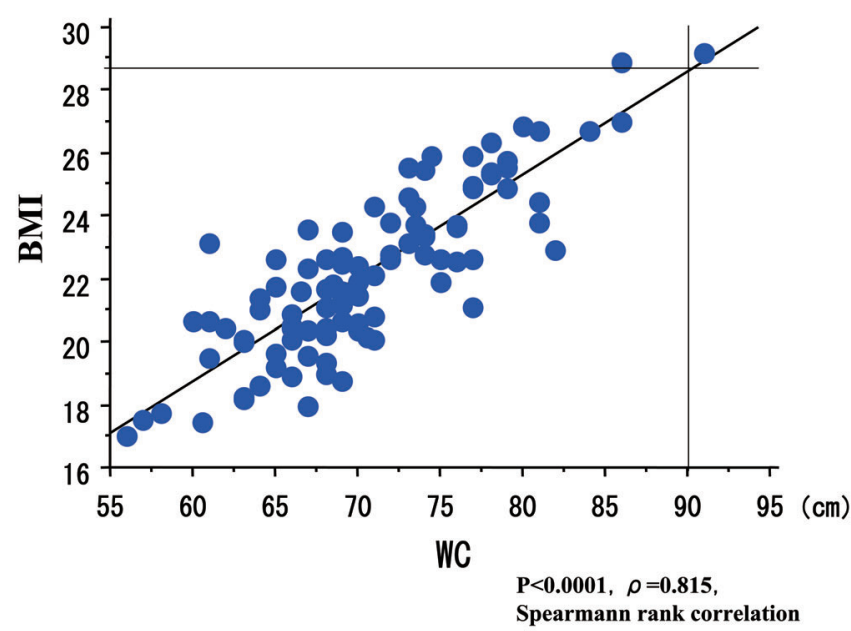

Figure 2. Correlation of body mass index (BMI) and waist circumference (WC) in women $(\mathrm{n}=99)$. A WC of $\geq 90 \mathrm{~cm}$ in men corresponded to BMIs of $\geq 29$. This data was collected from consecutive participants in our health screening of brain between March 2005 and October 2005.

metabolic syndrome without diabetes mellitus was a significant risk factor for ischemic stroke in both sexes, but the effect was more pronounced in women [Odds ratio $(\mathrm{OR}=$ 2.10)] than in men $(\mathrm{OR}=1.39)$ (11). The Framingham Offspring Study also reported that metabolic syndrome without diabetes mellitus was a significant risk factor for ischemic stroke in women $(\mathrm{OR}=2.8)$, whereas metabolic syndrome without diabetes mellitus did not increase the risk of ischemic stroke in men significantly (12). In another report, Iglseder et al. investigated the association between metabolic syndrome and early atherosclerosis of carotid arteries and found that the risk of atherosclerosis conferred by metabolic syndrome was more pronounced in females (20). On the other hand, Kurl et al reported that the risk of ischemic stroke is increased in men with metabolic syndrome significantly in Finland (13). The result of theirs might be due to the long follow-up period (average follow-up of 14.3 years). The present findings show that sex differences in the association of metabolic syndrome with ischemic stroke also exist in the Japanese population. Metabolic syndrome is generally considered to be a prediabetic condition $(9,21-23)$, and type 2 diabetes mellitus has been reported to increase the risk of stroke more in women than in men (24).

Why does metabolic syndrome have a greater influence on the risk of cerebral infarction in women than in men? First, some might think that perhaps the gender difference with respect to ischemic stroke and metabolic syndrome results from gender differences in diagnostic criteria for metabolic syndrome. We used BMI to define central obesity. As waist circumferences of $\geq 85 \mathrm{~cm}$ in men and $\geq 90 \mathrm{~cm}$ in women corresponded to BMIs of $\geq 25$ and $\geq 29$, respectively, we used these numbers as cut-off values for central obesity throughout the study. Using these cut-off values, the rate of metabolic syndrome in women was only one-tenth of that in men. The study might select only extremely obese women as subjects with metabolic syndrome in the study. 
Table 1. Clinical and Biochemical Characteristics at Baseline in Subjects with and without Metabolic Syndrome (Mean and SDs)

\begin{tabular}{|c|c|c|c|}
\hline & $\begin{array}{l}\text { Metabolic } \\
\text { Syndrome (-) }\end{array}$ & $\begin{array}{l}\text { Metabolic } \\
\text { Syndrome (+) }\end{array}$ & $P$ \\
\hline Males & $\mathrm{n}=683$ & $\mathrm{n}=84$ & \\
\hline Age, y & $61.9 \pm 5.9$ & $62.4 \pm 6.4$ & n.s. \\
\hline $\mathrm{BMI}, \mathrm{kg} / \mathrm{m}^{2}$ & $22.7 \pm 2.4$ & $26.7 \pm 1.5$ & $<0.001$ \\
\hline Smokers, \% & $53.6 \%$ & $61.9 \%$ & n.s. \\
\hline Alcohol habit, \% & $25.9 \%$ & $41.7 \%$ & 0.009 \\
\hline Systolic BP, mmHg & $128.6 \pm 19.5$ & $143.8 \pm 18.6$ & $<0.001$ \\
\hline Diastolic BP, mmHg & $77.0 \pm 11.5$ & $85.9 \pm 11.5$ & $<0.001$ \\
\hline Fasting glucose, $\mathrm{mg} / \mathrm{dl}$ & $100.9 \pm 8.5$ & $109.3 \pm 9.7$ & $<0.001$ \\
\hline $\mathrm{T}-\mathrm{cho}, \mathrm{mg} / \mathrm{dl}$ & $200.4 \pm 33.6$ & $200.6 \pm 33.2$ & n.s. \\
\hline Triglycerides, mg/dl & $116.3 \pm 70.6$ & $169.3 \pm 90.6$ & $<0.001$ \\
\hline $\mathrm{HDL}, \mathrm{mg} / \mathrm{dl}$ & $53.9 \pm 15.1$ & $44.8 \pm 12.0$ & $<0.001$ \\
\hline Af on ECG, \% & $1.5 \%$ & $1.1 \%$ & n.s. \\
\hline Hypertension, \% & $47.4 \%$ & $79.8 \%$ & $<0.001$ \\
\hline $\mathrm{T}-\mathrm{cho} \geq 240 \mathrm{mg} / \mathrm{dl}, \%$ & $12.6 \%$ & $12.0 \%$ & $\mathrm{n}, \mathrm{s}$. \\
\hline Antihypertensive drugs, \% & $19.6 \%$ & $36.9 \%$ & $<0.001$ \\
\hline Follow-up period, y & $6.5 \pm 3.8$ & $6.9 \pm 3.8$ & n.s. \\
\hline Females & $\mathrm{n}=718$ & $\mathrm{n}=8$ & \\
\hline Age, y & $61.8 \pm 5.1$ & $59.5 \pm 4.2$ & n.s. \\
\hline BMI, $\mathrm{kg} / \mathrm{m}^{2}$ & $22.8 \pm 2.7$ & $29.9 \pm 8.5$ & $<0.001$ \\
\hline Smokers, \% & $4.6 \%$ & $0 \%$ & n.s. \\
\hline Alcohol habit, \% & $2.2 \%$ & $0 \%$ & n.s \\
\hline Systolic BP, mmHg & $126.9 \pm 20.1$ & $146.4 \pm 20.1$ & 0.006 \\
\hline Diastolic BP, mmHg & $74.2 \pm 12.3$ & $83.3 \pm 10.5$ & 0.038 \\
\hline Fasting glucose, mg/dl & $98.7 \pm 8.9$ & $110.4 \pm 11.8$ & $<0.001$ \\
\hline $\mathrm{T}$-cho, mg/dl & $220.6 \pm 34.5$ & $252.0 \pm 33.4$ & $<0.01$ \\
\hline Triglycerides, mg/dl & $102.4 \pm 55.4$ & $143.4 \pm 41.4$ & 0.03 \\
\hline HDL, mg/dl & $60.6 \pm 14.8$ & $52.1 \pm 10.8$ & n.s. \\
\hline Af on ECG \% & $0.6 \%$ & $0 \%$ & n.s. \\
\hline Hypertension, \% & $43.9 \%$ & $62.5 \%$ & n.s. \\
\hline $\mathrm{T}-\mathrm{cho} \geq 240 \mathrm{mg} / \mathrm{dl}, \%$ & $27.4 \%$ & $50.0 \%$ & n.s. \\
\hline Antihypertensive drugs, \% & $19.9 \%$ & $12.5 \%$ & n.s. \\
\hline Follow-up period, y & $6.3 \pm 3.9$ & $4.5 \pm 2.7$ & n.s. \\
\hline
\end{tabular}

BMI:body mass index, BP:blood pressure, HDL: high-density lipoprotein cholesterol , Af:Atrial fibrillation, T-cho: total cholesterol

Therefore, we recalculated the data using lower BMI cut-off values for women (27 or 25). After altering the diagnostic criteria, metabolic syndrome was associated with an even higher incidence of ischemic stroke in women. A change in the BMI cut-off value for the male subjects (27 or 29) did not result in an association between metabolic syndrome and ischemic stroke in men. This indicates that the gender difference for ischemic stroke in relation to metabolic syndrome was not due to gender differences in the diagnostic criteria for metabolic syndrome. Secondly, although there were no differences in total cholesterol between men with and without metabolic syndrome, total cholesterol in women with metabolic syndrome was significantly higher than in women without metabolic syndrome in the study. It is well known that lipid abnormalities are associated with atherosclerosis. Metabolic syndrome might influence lipid abnormalities in women more than in men. Third, the circulating adiponectin level is inversely related to obesity (25) and has antidiabetic 


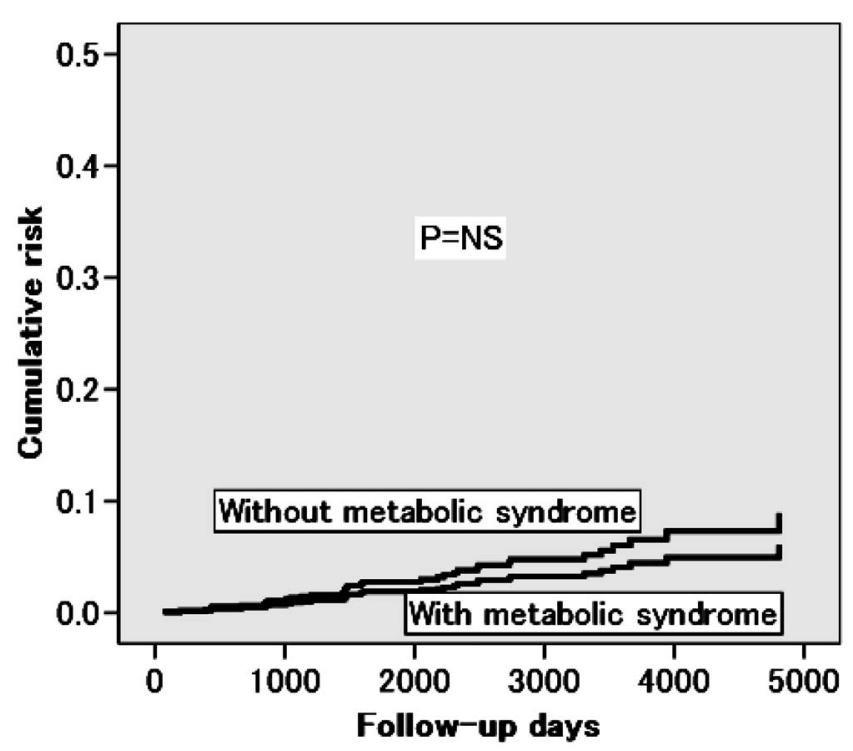

Figure 3A. Cumulative risks adjusted age and smoking for ischemic stroke in men with metabolic syndrome.

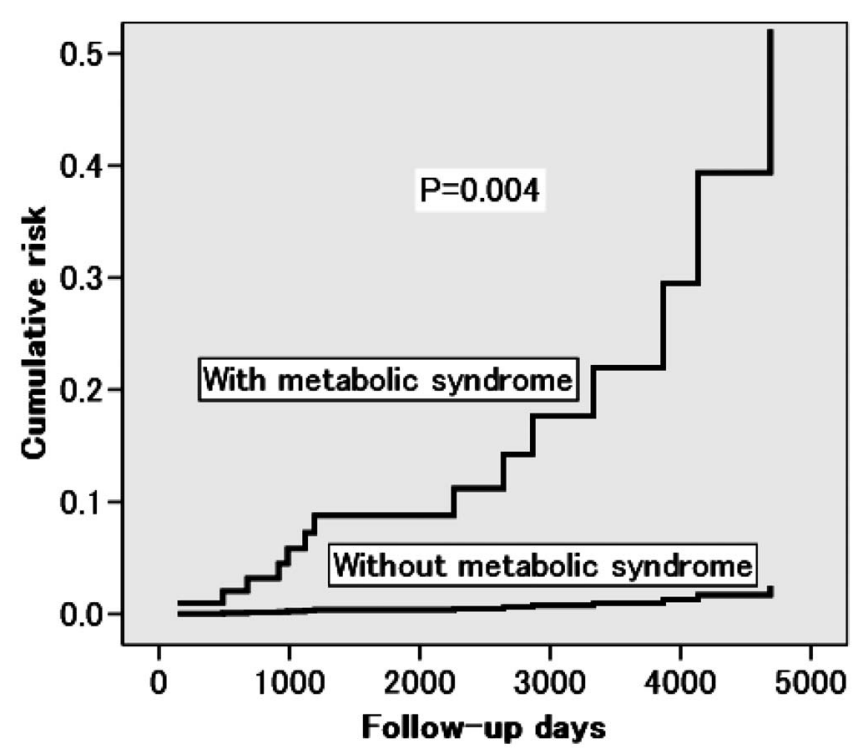

Figure 3B. Cumulative risks adjusted age and smoking for ischemic stroke in women with metabolic syndrome.

Table 2. The Incidence of Ischemic Stroke in Women Subjects with or without Metabolic Syndrome Followed-up 3 to 6 Years

\begin{tabular}{llll}
\hline & $\begin{array}{l}\text { Metabolic } \\
\text { Syndrome (-) } \\
(\mathrm{n}=196)\end{array}$ & $\begin{array}{l}\text { Metabolic } \\
\text { Syndrome (+) } \\
(\mathrm{n}=4)\end{array}$ & $P^{*}$ \\
\hline $\begin{array}{l}\text { Ischemic stroke } \\
\text { * Fisher's exact test }\end{array}$ & 1 & 1 & 0.04 \\
\hline Values are number of subjects & & & \\
\hline
\end{tabular}

and anti-atherogenic effects (26). However the adiponectin level is generally higher in women than in men (27), Kojima et al showed that a reduction from high plasma adiponectin concentrations could trigger the progression of coronary atherosclerosis, especially in women (28). Although we did not examine the adiponectin level, we think that it is possible that the reduction in adiponectin with metabolic syndrome might induce the onset of ischemic stroke in women.

Central obesity is the essential component for the diagnosis of metabolic syndrome in Japan. This diagnostic criterion is based on the hypothesis that metabolic syndrome does not result from the coincident combination of risk factors, but rather from visceral obesity, which predisposes individuals to the development of diabetes mellitus, dyslipidemia, and hypertension (29). Two previous cohort studies showed that BMI is a risk factor for stroke in men $(30,31)$. These results seem to be inconsistent with our results, although the follow-up periods in those studies (15 years and 12.5 years) were longer than in our study $(6.3 \pm 3.8$ years $)$. Had we followed the male subjects in our study for a longer period of time, the occurrence of ischemic stroke might have been dif- ferent in male subjects with metabolic syndrome than in those without metabolic syndrome.

One limitation of our study is that it was not a community-based study. The study subjects were individuals who volunteered for neurology checkups in the interest of their own health, and might not be representative of the general population. Another limitation is that there were only a few women with metabolic syndrome in the study. This might have been due to the metabolic syndrome criteria for Japanese populations published in April 2005. Using these criteria to diagnose metabolic syndrome, the rate of excess waist circumference in women subjects might be extremely low in Japan.

Although the generalization is limited by the potential bias in subject selection, this study suggests that metabolic syndrome is more likely to influence the risk for ischemic stroke in women than in men. Further community-based studies in Asia are necessary to confirm these results.

This research was supported by grants from the Japan Society for the Promotion of Science (1998-2000), the Japan Arteriosclerosis Prevention Fund (2001), Shimane Institute of Health Sci- 


\section{References}

1. Grundy SM, Brewer HB Jr, Cleeman JI, Smith SC Jr, Lenfant C. Definition of metabolic syndrome: Report of the National Heart, Lung, and Blood Institute/American Heart Association conference on scientific issues related to definition. Circulation 109: 433-438, 2004.

2. Expert Panel on Detection, Evaluation, and Treatment of High Blood Cholesterol in Adults. Executive summary of the third report of the National Cholesterol Education Program (NCEP) expert panel on detection, evaluation, and treatment of high blood cholesterol in adults (Adult Treatment Panel III). JAMA 285: 2486-2497, 2001.

3. Hu G, Qiao Q, Tuomilehto J, Balkau B, Borch-Johnsen K, Pyorala K, DECODE Study Group. Prevalence of the metabolic syndrome and its relation to all-cause and cardiovascular mortality in nondiabetic European men and women. Arch Intern Med 164: 1066-1076, 2004.

4. Marroquin OC, Kip KE, Kelley DE, et al. Metabolic syndrome modifies the cardiovascular risk associated with angiographic coronary artery disease in women: a report from the Women's Ischemia Syndrome Evaluation. Circulation 109: 714-721, 2004.

5. Ford ES. The metabolic syndrome and mortality from cardiovascular disease and all-cause: findings from the National Health and Nutrition Examination Survey II Mortality Study. Atherosclerosis 173: 309-314, 2004.

6. Isomaa $\mathrm{B}$, Almgren $\mathrm{P}$, Tuomi $\mathrm{T}$, et al. Cardiovascular morbidity and mortality associated with the metabolic syndrome. Diabetes Care 24: 683-689, 2001.

7. Lakka HM, Laaksonen DE, Lakka TA, et al. The metabolic syndrome and total and cardiovascular disease mortality in middleaged men. JAMA 288: 2709-2716, 2002.

8. Klein BE, Klein R, Lee KE. Components of the metabolic syndrome and risk of cardiovascular disease and diabetes in Beaver Dam. Diabetes Care 25: 1790-1794, 2002.

9. Malik S, Wong ND, Franklin SS, et al. Impact of the metabolic syndrome on mortality from coronary heart disease, cardiovascular disease, and all causes in United States adults. Circulation 110: 1245-1250, 2004.

10. Boden-Albala BM, Lee HS, Paik MC, et al. Stroke risk and the metabolic syndrome: findings from the Northern Manhattan Study. Neurology 60 (Suppl 1): 255-256, 2003 (Abstract).

11. Koren-Morag N, Goldbourt U, Tanne D. Relation between the metabolic syndrome and ischemic stroke or transient ischemic attack: A prospective cohort study in patients with atherosclerotic cardiovascular disease. Stroke 36: 1366-1371, 2005.

12. Najarian RM, Sullivan LM, Kannel WB, Wilson PW, D'Agostino $\mathrm{RB}$, Wolf PA. Metabolic syndrome compared with type 2 diabetes mellitus as a risk factor for stroke. The Framingham Offspring Study. Arch Intern Med 166: 106-111, 2006.

13. Kurl S, Laukkanen JA, Niskanen L, et al. Metabolic syndrome and the risk of stroke in middle-aged men. Stroke 37: 806-811, 2006.

14. Tan CE, Ma S, Wai D, Chew SK, Tai ES. Can we apply the National Cholesterol Education Program Adult Treatment Panel definition of the metabolic syndrome to Asians? Diabetes Care 27: 1182-1186, 2004

15. Alberti KG, Zimmet P, Shaw J. IDE Epidemiology Task Force
Consensus Group. The metabolic syndrome- $-\mathrm{a}$ new worldwide definition. Lancet 366: 1059-1061, 2005.

16. Kubo M, Kiyohara Y, Kato I, et al. Trends in the incidence, mortality and survival rate of cardiobvascular disease in a Japanese community. the Hisayama Study. Stroke 34: 2349-2354, 2003.

17. Lerner DJ, Kannel WB. Patterns of coronary heart disease morbidity and mortality in the sexes: a 26-year follow-up of the Framingham population. Am Heart J 111: 383-390, 1986.

18. Wolf PA, D'Agostino RB, Kanne WB, Bonita R, Belanger AJ. Cigarette smoking as a risk factor for stroke. JAMA 259: 10251029, 1988.

19. Metabolic Syndrome Criteria Study Group. Definition and criteria for metabolic syndrome. Nippon Naika Gakkai Zasshi 94: 188203, 2005 (in Japanese).

20. Iglseder B, Cip P, Malaimare L, Ladurner G, Paulweber B. The metabolic syndrome is a stronger risk factor for early carotid atherosclerosis in women than in men. Stroke 36: 1212-1217, 2005.

21. Resnick HE, Jones $\mathrm{K}$, Ruotolo $\mathrm{G}$, et al. Insulin resistance, the metabolic syndrome, and risk of incident cardiovascular disease in nondiabtic American Indians: the STRONG Heart Study. Diabetes Care 26: 861-867, 2003.

22. Lorenzo C, Okoloise M, Williams K, Stern MP, Haffner SM, San Antonio, Heart Study. The metabolic syndrome as predictor of type 2 diabetes: the San Antonio Heart Study. Diabetes Care 26: 3153-3159, 2003.

23. Brantsma AH, Bakker SJ, Hillege HL, de Zeeuw D, de Jong PE, Gansevoort RT, PREVEND Study Group. Urinary albumin excretion and its relation with C-reactive protein and the metabolic syndrome in the prediction of type 2 diabetes. Diabetes Care 28: 2525-2530, 2005.

24. Stegmayr B, Asplund K. Diabetes as a risk factor for stroke. A population perspective. Diabetologia 38: 1061-1068, 1995.

25. Cnop M, Havel PJ, Utzschneider KM, et al. Relationship of adiponectin to body fat distribution, insulin sensitivity and plasma lipoproteins: evidence for independent roles of age and sex. Diabetologia 46: 459-469, 2003.

26. Kadowaki T, Yamauchi T. Adiponectin and adiponectin receptors. Endocr Rev 26: 439-451, 2005.

27. Laughlin GA, Barrett-Connor E, May S. Sex-specific association of the androgen to oestrogen ratio with adipocytokine levels in older adults: the Rancho Bernardo Study. Clin Endocrinol 65: 506-513, 2006.

28. Kojima S, Funahashi T, Otsuka F, et al. Future adverse cardiac events can be predicted by persistently low plasma adiponectin concentrations in men and marked reductions of adiponectin in women after acute myocardial infarction. Atherosclerosis (2006) doi:10.1016/j.atherosclerosis.2006.07.028.

29. Uchiyama S. Impact of metabolic syndrome as a risk factor for atherothrombotic stroke. Intern Med 44: 1021-1022, 2005.

30. Dey DK, Rothenberg E, Sundh V, Bosaeus I, Steen B. Waist circumference, body mass index, and risk for stroke in older people: a 15 year longitudinal population study of 70-year-olds. J Am Geriatr Soc 50: 1510-1518, 2002.

31. Kurth T, Gaziano JM, Berger K, et al. Body mass index and the risk of stroke in men. Arch Intern Med 162: 2557-2562, 2002.

(C) 2007 The Japanese Society of Internal Medicine http://www.naika.or.jp/imindex.html 